\title{
Analysis of Standardized Nursing Languages Application in the Context of Nursing Diagnosis in Hospital in Indonesia
}

\author{
Irman Somantri ${ }^{1 *}$ (D), Nanan Sekarwana ${ }^{2}$, Ati Surya Mediawati ${ }^{1}$, Vimala Ramoo ${ }^{3}$ (D), Nor Aziyan Yahaya ${ }^{3}$, \\ Kurniawan Yudianto ${ }^{1}$ D
}

${ }^{1}$ Department of Fundamental Nursing, Faculty of Nursing, Padjadjaran University, Sumedang, Indonesia; ${ }^{2}$ Department of Child Health, Faculty of Medicine, UNISBA, Bandung, Indonesia; ${ }^{3}$ Department of Nursing Science, Faculty of Medicine, University of Malaya, Kuala Lumpur, Malaysia

Edited by: Mirko Spirosk NA, Yuna N, Mediawati As, Ramoo V, Yahaya NA, Yudianto K. Analysis of Standardized Nursing Losis in Hospital in Indonesia. OpenAccess Maced J Med Sci. 2021 Dec 06:9(T6):173-178. https://doi.org/10.3889/oamjms.2021.7307
. Keywords: Nursing; Standardized nursing languages; Nursing languages; Nursing diagnosis Correspondence: Irman Somantri, Department of Fundamental Nursing, Faculty of Nursing, Padjadjaran Unversity, Sumedang, Indonesia. -mail: irman.somantri@unpad.ac.id Revised: 09-Nov-2021 Accepted: 26-Nov-2021 Copyright: (๑) 2021 Irman Somantri, Nanan Sekarwana, Ati Surya Mediawati, Vimala Ramoo, Nor Aziyan Yahaya, Kurniawan Yudianto Funding: This study was supported by Padjadjaran Competing Interests: The authors have declared that no competing interests exis Open Access: This is an open-access article distribute under the terms of the Creative Commons Attribution-

\begin{abstract}
BACKGROUND: Documentation of nursing care is important in applying care to patients, in terms of their workload coming into the context of indirect nursing care. The focus of his study is to assess the application of nursing diagnoses in hospitals. The phenomenon that occurs in the order of nursing services was found that nurses only focused on documenting nursing assessments, but formulating nursing diagnoses was not clearly illustrated, and there are still different perceptions in relation to writing a nursing diagnosis phrase.

AIM: The purpose of this study is to identify The Relationship of Nurse Demographic Characteristics with the Application of Nursing Diagnosis in the Government Hospital of Bandung City, Indonesia.

METHODS: This study uses a descriptive correlation design using simple random sampling and obtained 132 nurse respondents. Closed questions (with answer choices prepared by the researcher), and open questions (in the form of frequently used diagnostic questions) were used. The instrument was first tested for validity and content validity with a Content of Validity Index (0.9) and Content of validity Ratio $(0.85)$ value, which means that the instrument is relevant and important to use.

RESULTS: It was found that almost half of the respondents $(48.49 \%)$ nurses did not use a standard diagnosis. Only the level of education has a relationship with the application of the use of standard language nursing in Indonesia $(p=0.006)$ where the higher the education of nursing will have an impact on accuracy in diagnosing. Whereas for other variables such as gender, career ladder level and position in nursing were found no relationship with the ability in the accuracy of writing diagnoses.

CONCLUSION: As the results, it shows that the use of the standard language of nursing is not fully used by nurses in Indonesia. Standardization and equalization of perception by nursing professional organizations are needed to be
\end{abstract} a guide for all nurses in carrying out documentation of nursing care.

\section{Introduction}

Nursing encompasses autonomous and collaborative care of individuals of all ages, families, groups and communities, sick or well and in all settings. It includes the promotion of health, the prevention of illness, and the care of ill, disabled and dying people [1].

In Indonesia, the nursing process is known in five steps that synergize and run continuously in a cycle that starts from assessment, formulation of diagnosis, planning, implementation, and evaluation. Of the five steps will determine the actions that must be taken by nurses, the wrong diagnosis will also produce the wrong actions that make treatment ineffective [2].

The use of standardization of nursing language has many benefits for nurses who deal with patients directly, including: establishing better communication between nurses and other health workers, increasing the ability of nursing interventions, improving patient care, increasing data collection to evaluate the results of nursing care, increasing adherence to standards of care, and facilitate examination of nurse competencies. Using standard language nursing, nurses around the world will be able to communicate with each other, with the aim of improving overall patient care [3].

Research on the standard language of nursing has also been carried out by researchers in several countries, including in Nigeria, it was found that the nursing process and the use of nursing diagnoses based on taxonomy from the North American Nursing Diagnosis Association-International (NANDA-I) found that nursing diagnoses have been included in nursing education since 1980, but the concept of the Nursing Outcomes Classification (NOC) and Nursing Intervention Classification (NIC) is still relatively new and only a small proportion of nurses know it [4]. This is in line with the results of other studies where it was found that about $60.0 \%$ of nurses know the steps of the nursing process of which only $5.4 \%$ can correctly define the language of nursing standards. Only $26.2 \%$ have 
good knowledge. The use of Standardized Nursing Languages (SNLs) by nurses shows that the majority $(83.8 \%)$ of nurses agree to use SNLs that can improve the quality of service [5], [6].

The concept of NANDA, NIC, and NOC can be used as a standard of nursing language where three concepts can be manifested in nursing actions toward patients; nurses need to absorb the use of terminological content from three concepts aimed at increasing the achievement of care goals to patients [7].

Several research results related to the use of standard language in nursing in Indonesia have long been studied. The results of the study of several nurses in three hospitals in the city of Bandung and Cimahi Indonesian found any variations in the writing of the name of nursing diagnosis, in fact it was not only done by implementing nurses who were familiar with daily routine work behavior patterns, even lecturers who taught the nursing process often provide input to students using their personal perceptions which in turn will blame each other with one lecturer or another nurse or one another for phrases from the nursing diagnosis [8].

The results of a survey conducted in Yogyakarta, stating that there are at least 15 variations in the language used by nurses to describe one and the same problem. He gave an example: For nursing pain problems, some use the sentence: "Gangguan rasa nyaman" (disturbance of comfort), "Gangguan rasa nyaman nyeri" (Pain Discomfort), "Ketidaknyamanan" (Discomfort), "Gangguan nyeri" (Pain Disorders), and others [9].

Based on the phenomena obtained at three institutions of nursing higher education and three institutions of health services in the city area of Bandung, there was an inconsistency of language in nursing documentation, including the Nursing Standards that have been recorded by the health care institution for one type of nursing diagnosis label which has a different sentence. Clarification from the nursing committee section said that the standard setting was not carried out scientifically, but was left to only certain nurses who were selected by the nursing leader without looking at competence, and the results of making a diagnosis were not carried out theoretical verification but were immediately made into standards. The purpose of this study was to identify the relationship between the demographic characteristics of nurses and the application of SNLs in the context of nursing diagnoses.

\section{Methods}

This study uses a descriptive correlative design that assesses correlation between nurse characteristic with the application of SNLs. The sample in this study was nurses in two government hospitals in the Bandung city area of Indonesia using simple random sampling techniques obtained and willing to be respondents as many as 132 nurses.

The instrument in this study was developed by researchers using closed questions about aspects of biography and basic questions about SNLs taken from examination questions for competency tests, as well as open questions to test understanding of aspects of requirements for diagnosis and then analyzing content to infer respondents. To guarantee the strength of the instrument, validity and reliability tests are carried out. The validity test used is the face validity technique, as well as the content validity test for two experts in the field of nursing management, the results obtained are the validity coefficient values for Content of validity Ratio $=0.85$ and Content of Validity Index $=0.9$, which means that the instrument is be relevant and is very useful to use.

In this study, the nursing diagnosis standard uses the NANDA label and a new standard developed in Indonesia, the Indonesian Nursing Diagnosis Standard as a complement. The results of the study are presented in the form of a frequency distribution table while the results of the interviews are included in the discussion to strengthen the explanation of the research results. For bivariate data analysis, use the Chi-square test.

\section{Results}

Table 1 explains the sources of literature used by respondents, where respondents were allowed to answer more than one answer. Percentages are displayed as percentages based on total measurement results but compared to the number of respondents per measurement result.

Table 1: Sources of literature used

\begin{tabular}{lll}
\hline Measuring result & Frequency & $\%$ \\
\hline Teacher & 74 & 56.06 \\
Text book & 66 & 50 \\
Co-workers & 36 & 27.27 \\
Senior nurse & 6 & 4.55 \\
Internet & 2 & 1.14 \\
\hline The percentage is calculated based on the frequency of answers divided by total sample $(132) \times 100 \%$, \\
respondents can choose $>1$ answer.
\end{tabular}

Table 1 shows the sources from which nurses determine nursing diagnoses. In this case, a closed questionnaire was used where the nurse was allowed to choose more than one answer that was considered appropriate for her. It was found that most of the nurses $(56.06 \%)$ got knowledge about the diagnosis formulation from the teacher. Half of the samples stated that the reference in formulating the diagnosis was through textbooks (50\%) and the rest stated that they came from colleagues $(27.27 \%)$, senior nurses $(4.55 \%)$, and at least came from the internet $(1.14 \%)$. 
Table 2 contains the frequency distribution of diagnosis uses based on the characteristics of the respondents, where the instrument used is in the form of questions that must be answered openly by the respondent (the researcher did not provide a diagnostic label limit). And obtained as follows:

Table 2 shows the frequency distribution of the use of nursing diagnosis labels based on the characteristics of the respondents, data obtained univariately where a total of almost half of the respondents $(48.49 \%)$ nurses did not use a standard diagnosis.

A correct diagnosis means that the diagnosis used by nurses is in accordance with the standards agreed on by nurse organizations in Indonesia. Incorrect diagnosis means that the diagnosis used by the nurse is actually in accordance with the standards agreed upon by the nurse organization in Indonesia but misdiagnoses according to the problems that arise in the patient while non-standardized diagnosis means that the diagnosis made by the nurse is not based on any standard.

Based on gender, it is known that from a total of 16 male nurses, only $31.2 \%$ were able to correctly diagnose the patient's problem, as well as for female nurses from 116 people, only $28.4 \%$ were able to correctly diagnose. The results of the correlation test using Chi-square obtained a p-value of 1.0, which means that there is no relationship between gender and the ability to use nursing diagnosis labels.

Based on the level of education of nurses, it is known that from a total of 98 nurses with diploma education, $21.4 \%$ of them are able to diagnose nursing problems correctly, while for undergraduate graduates, $50 \%$ of 34 nurses are able to diagnose correctly. The results of the correlation test using Chi-square obtained a p-value of 0.006 , which means that there is a relationship between the level of nurse education and the ability to use nursing diagnosis labels.

At present in Indonesia, a clinical nurse career ladder is being developed with levels ranging from prepractitioner nurse to practitioner nurse level 5 . Based on the results of the study, it was found that from all nurse career levels it was found that nurse practitioner 1 had the highest correct nursing diagnosis ability compared to others, of 14 people $50 \%$ of whom were able to formulate nursing. Correctly diagnosed, followed by preclinical nurses by $35.7 \%$. As for the other, the ability to formulate nursing diagnoses under the two career paths that have been mentioned. The results of the bivariate test with Chi-square did not find a relationship between the career ladder of nurses and the ability to apply nursing diagnoses in Indonesia, with a p-value of 0.547.

In accordance with the nurse hierarchy, it can be seen that all nurses from 4 levels have almost the same percentage of ability in formulating nursing diagnoses correctly. Nurse manager has the highest percentage in the ability to diagnose correctly compared to the other three positions, which is $30.8 \%$, while nursing supervisor has the lowest ability among the others. That is, only $25 \%$ are able to formulate a diagnosis correctly. The results of the bivariate test with Chi-square did not find a relationship between the nurse hierarchy and the ability to apply nursing diagnoses in Indonesia, with a p-value of 0.977 .

\section{Discussion}

The study began with questions that contained a general picture of the patient's condition. In this research instrument, the researchers used cases drawn from basic data of patients with respiratory system problems, on the mechanism of the ventilation process. In the NANDA 2018-2020 standard in domain 11 (safety/protection) class 2 (physical injury) labeled "ineffective airway breathing." Based on the results obtained, most nurses still use diagnostic labels that are not in accordance with standards, this will result in incomplete nursing care by nurses to patients [10]. The use of a uniform nursing diagnosis label is very important to be used by all nurses, which will make it easier to find patient medical records [11].

Table 2: Frequency distribution of nursing diagnosis based on demographic data $(n=132)$

\begin{tabular}{|c|c|c|c|c|c|}
\hline \multirow[t]{2}{*}{ Variables } & \multicolumn{4}{|c|}{ Using of nursing diagnosis label } & \multirow[t]{2}{*}{$p$ value } \\
\hline & Correct diagnosing & Incorrect diagnosing & Non standardized diagnosis & Total & \\
\hline \multicolumn{6}{|l|}{ Sex } \\
\hline Male & $5(31.2 \%)$ & $3(18.8 \%)$ & $8(50 \%)$ & 16 & \multirow[t]{2}{*}{1.0} \\
\hline Female & $33(28.4 \%)$ & $27(23.3 \%)$ & $56(48.3 \%)$ & 116 & \\
\hline \multicolumn{6}{|l|}{ Level of nurse education } \\
\hline Diploma & $21(21.4 \%)$ & $24(24.5 \%)$ & $53(54.1 \%)$ & 98 & \multirow[t]{2}{*}{0.006} \\
\hline BSN & $17(50 \%)$ & $6(17.6 \%)$ & $11(32.4 \%)$ & 34 & \\
\hline \multicolumn{6}{|c|}{ Indonesian level of carrier ladder } \\
\hline Pra nurse practitioner & $10(35.7 \%)$ & $6(21.4 \%)$ & $12(42.9 \%)$ & 28 & \multirow[t]{5}{*}{0.547} \\
\hline Nurse practitioner 1 & $7(50 \%)$ & $3(21.4 \%)$ & $4(28.6 \%)$ & 14 & \\
\hline Nurse practitioner 2 & $8(21.1 \%)$ & $8(21.1 \%)$ & $22(57.9 \%)$ & 38 & \\
\hline Nurse practitioner 3 & $12(27.3 \%)$ & $10(22.7 \%)$ & $22(50 \%)$ & 44 & \\
\hline Nurse practitioner 4 & $1(12.5 \%)$ & $3(37.5 \%)$ & $4(50 \%)$ & 8 & \\
\hline \multicolumn{6}{|l|}{ Nurse hierarchy } \\
\hline Staff nurse & $26(29.5 \%)$ & $20(22.7 \%)$ & $42(47.7 \%)$ & 88 & \multirow[t]{5}{*}{0.977} \\
\hline Team leader nurse & $5(26.3 .0)$ & $4(21.2 \%)$ & $10(52.6 \%)$ & 19 & \\
\hline Nurse manager & $4(30.8 \%)$ & $4(30.8 \%)$ & $5(38.5 \%)$ & 13 & \\
\hline Nurse supervisor & $3(25 \%)$ & $2(16.7 \%)$ & $7(58.3 \%)$ & 12 & \\
\hline Total & $38(28.79 \%)$ & $30(22.72 \%)$ & $64(48.49 \%)$ & 132 & \\
\hline
\end{tabular}


The Table 2 which is categorized as "In correct diagnosing" in this study means that the label is conceptually contained in the standard but the nurse turns out to be wrong in establishing the diagnosis, the labels that appear are: "Ineffective Breathing Patterns" and "Impaired Gas Exchange." Diagnoses are listed in the NANDA diagnosis standard, but it is a false diagnosis if seen from the signs and symptoms that appear in the research instrument. Both diagnoses are in the NANDA standard in Domain 3 (elimination and exchange) in class 4 (respiration function) for Impaired Gas Exchange diagnosis, as well as in Domain 4 (activity/rest) class 4 (Cardiovascular/Pulmonary Response) for ineffective breath pattern [12].

The results of the study labeled the statement "non standardized nursing diagnosis" means that the diagnosis mentioned by the respondent does not have a standard. Labels that used by respondents to label this diagnosis include: uncomfortable cough, impaired ventilation, impaired oxygen and carbon dioxide fulfillment, respiratory problems, and other.

Nursing diagnoses must be documented in clear terms with definitions and diagnostic labels. Part of the nursing documentation includes etiology or related factors and signs and symptoms or defining characteristic that will eventually form the basis for the formulation of nursing orders, also known as the PES format [12].

In the world of education the use of SNLs plays a role in increasing nurse competence, this is consistent with the results of research in which the continuing nursing education language standard program has a significant influence on the quality of care documentation using Nursing Language Standards [4].

The results of this study also found that most nurses did not use existing nursing diagnosis standards, they made nursing diagnoses based on their assumptions and used language according to the language they understood. The use of non-standard language will result in disagreement in the diagnosis label which will ultimately lead to discontinuity in nursing care performed by nurses. This is even consistent with what is stated in the reference where the use of accurate labels will also increase the accuracy of nursing care [13]. Standard language will make it easier for nurses to be able to make treatment goals and intervention plans that must be done by nurses to overcome patient problems [14].

The instrument in this study also tried to uncover the reasons for the nursing diagnosis by nurses. Errors that occur in the form of errors in determining the label and determine the defining characteristics of nursing diagnosis. Based on interview results, it was found that nurses who responded generally stated that they did not understand the definition of nursing diagnosis and when were asked questions in the form of data; they were confused to determine the right nursing diagnosis, and this was also related to nurses understanding of the main data that must be obtained from the nursing diagnosis.

The defining characteristic of a diagnosis is a sign and symptom which is divided into major data which means that signs and symptoms must appear to be able to establish a diagnosis as well as minor data which are complementary data from the main data earlier [14].

Based on research found that nursing education contributes to the understanding of nurses to apply the correct nursing diagnosis label. This is consistent with the results of research from lyabode (2017) which stated that education will not have a significant effect on writing diagnostic labels. The major challenges identified by the respondents include poor knowledge of the language, lack of basic amenities, poor policy, inefficient continuous education, and shortage of manpower [6], [15].

It was also found that some respondents stated that teachers $(56.06 \%)$ and textbooks $(50 \%)$ were the main references in determining nursing diagnoses. The results of clarification to respondents using interview techniques was found that the type of book that was often used is surgical nursing books. However, after conducting in-depth questions, it turned out that respondents stated the contents of the material read were more of a pathophysiological process of the disease, and when to apply it in their daily work, it was often skipped because was considered to be meaningless.

Knowledge and attitudes of nurses in Nigeria in the formulation of a diagnosis found $12.6 \%$ weak in the use of SNLS this happened as a result of hospital policies, knowledge and young age of nursing staff but also found around 83.5 who had a positive attitude towards the use of these standards [16].

It was found that the gender of the nurse did not have a direct relationship with the application of the use of nursing diagnoses. This can happen because the nurse's task in documenting is not directly limited by gender, but is related to other factors that will clearly affect the ability to apply a diagnosis, there is no consistent difference between men and women in problem solving ability, analytical ability, motivation and learning ability. However, gender needs to be a concern because in a professional context gender is not the main obstacle [17].

The results showed that the level of education was related to the ability of nurses to apply standard nursing diagnosis language, where the higher the education, the higher the ability to apply nursing diagnoses. this is in accordance with one study where it was found that nursing experience, including in the application of a theory, was influenced by organizational culture and units in decision making; education; understand the patient's status; situation 
awareness; and autonomy [18]. Understanding of the formulation of nursing diagnoses has now been applied in the form of curricula in several countries, some of which are obtained where educational programs are used as a basis for improving nurses' abilities in using diagnoses and assisting the analysis process so that the quality of documentation increases [19]. In Kenya, data were obtained based on the results of the study, which turned out to be two-thirds of the nurses who were respondents had low knowledge of the nursing process [20].

Increasing student competence towards diagnosis and intervention will have a positive effect on the outcome of the patient's health status. The use of diagnoses, outcomes, and interventions will help improve critical thinking skills. One of the strategies used to help understand and implement SNL is to use a nursing student documentation package developed by the faculty. Educational strategies provide opportunities for students to enhance their experience with SNL, to be able to plan and document nursing care for individuals with physical and mental health problems [21].

A career ladder program is being developed in Indonesia which is a big investment. The impact of the implementation of the career ladder program is that nurse managers have a significant role in increasing the application of career ladder in order to increase job satisfaction among nurses [22]. The Career Ladder Program is one way for clinical nurses to advance their career through validation of professional development, leadership, and education. Career Ladder is designed to engage nurses in the support of the Patient Care Services Mission, to provide sciencebased, technologically precise, compassionately delivered patient care. Based on this, the application of career paths in Indonesia should have an impact on the performance of nurses, including the ability to make a diagnosis. However, in this study, it was found that there was no difference in the proportion of career paths between these nurses. This happens because the career path process in Indonesia is currently still in the development stage, which means that the nurse's credential process to reach that level has not been determined in accordance with the appropriate competencies; at present, it is still a nurse-based mapping on education and years of service only, excluding other assessments.

The results showed that there was no relationship between the hierarchy of nursing positions and the ability to apply nursing diagnoses; this was not in line with several other studies which showed that organizational variables could have a relationship with the ability of nurses to document diagnoses. Research in Turkey shows that workload and technological support are the organizational variables that have the most influence on their job performance [23].

\section{Conclusion}

Based on the results of the study, it was found that there were many ways for nurses to gain knowledge in terms of applying nursing diagnoses. Although most nurses stated that they received information about nursing diagnoses from source books, it turned out that only $28.79 \%$ were able to apply nursing diagnoses correctly, $22.72 \%$ were misdiagnosed and in fact most nurses in Indonesia made nursing diagnoses that were not based on standards. Furthermore, obtained results where there is a relationship between the levels of education with the ability of nurses in applying nursing diagnoses, where the higher the education of nurses, the higher the ability to apply nursing diagnoses in documentation.

The recommendation from this study is that there is a need for policies to increase the level of nurse education by every nursing manager. The improvement of the nursing curriculum that originally focused on medical diagnosis, it is time now to make the nursing diagnosis as the basis for the delivery of material, development of standardization for nursing language as part of an evaluation of nurses for competency achievement.

\section{Acknowledgment}

The authors would like to thank the respondents at two government hospitals in Bandung, Indonesia who were willing to accept to take part in this study. The authors also thank the management of the selected health care facilities for providing the author with the opportunity to conduct research and also to Padjadjaran University which has assisted in financing through internal research schemes.

\section{Ethical Clearance}

Ethical clearance was taken from the research ethics commission information system Padjadjaran University with the Reference number 154/UN6.KEP/ EC/2021.

\section{References}

1. World Health Organization. Nursing. Geneva: World Health Organization; 2013. Available from: https://www.who.int/topics/ nursing/en. [Last Accessed on 2021 May 01] 
2. Lembaran Negara Republik Indonesia, Law Number 38 about Nursing; 2014.

3. Rutherford MA. Standardized nursing language: What does it mean for nursing practice? Online J Issues Nurs. 2008;13(1):1-5.

4. Adubi IO, Olaugun AA, Adejumo PO. Effect of Standardized Nursing Language Continuing Education Programme on Nurses' Documentation of Care at University College Hospital, Ibadan. Bethesda, Maryland, US: National Center of Biotechnology Information; 2018. https://doi.org/10.1002/nop2.108

5. Olatubi MI, Oyediran OO, Faremi FA, Salau OR. Knowledge, Perception, and Utilization of Standardized Nursing Language (SNL) NNN among Nurses in Three Selected Hospitals in Ondo State, Nigeria; 2017. https://doi.org/10.1111/2047-3095.1219

6. Iyabode AS. Knowledge and use standardized nursing languages: A study among nurses at the federal medical Centre, Owo, Ondo state, Nigeria. Textila Int J. 2017;3(2):1-11. https:// doi.org/10.21522/tijnr.2015.03.02.art004

7. Oreofe Al, Oyenike AM. Transforming practice trough nursing innovative patient centered care: Standardized nursing languages. Int J Caring Sci. 2018;11(2):1319-22.

8. Somantri I. Fundamental of Nursing. Cimahi: Stikes A Yani Press; 2006.

9. AchmadiA. Overview of the NANDANOC NIC Nursing Diagnosis Application for Schizophrenic Patients in the MPKP Room, Prof. Mental Hospital. dr. Soeroyo Magelan, 29 April; 2010. Available from: http://eprints.undip.ac.id/14500/1/2004MIKM3184.pdf [Last accessed on 2019 Jan].

10. Somantri I, Adiningsih D, Emaliyawati E. Analysis of the Application of Standardized Nursing Language in the Context of Nursing Diagnosis in Hospitals, in Seminar Nasional Keperawatan Unpad, Bandung; 2018.

11. Paans W. Accuracy of Nursing Diagnoses: Knowledge, Knowledge Sources and Reasoning Skills. Leuven: Khatolieke Universiteit; 2011.

12. NANDA International Inc. Nursing Diagnoses Definitions and Classification 2018-2020. New York: Thieme; 2018.

13. Doenges ME, Moorhouse MF. Application of Nursing Process and Nursing Diagnoses: An Interactive Text for Diagnostic Reasoning. $6^{\text {th }}$ ed. Philadelphia, PA: F. A. Davis Company; 2013.

14. Carpenito LJ. Nursing Diagnosis: Application to Clinical Practice. Philadelphia, PA: Lippincott; 2016.

15. Olson A, Rencic J, Cosby K, Rusz D, Papa F, Croskerry P, Zierler $\mathrm{B}$, et al. Competencies for improving diagnosis: An interprofessional framework for education and training in health care. Diagnosis (Berl). 2019;6(4):335-41. https://doi. org/10.1515/dx-2018-0107

PMid:31271549

16. Sani AM, Sani S. Nurse attitude and barriers toward utilization of standardized nursing language in Sokoto state, Nigeria. Asian J Med Health. 2017;2(2):1-6. https://doi.org/10.9734/ ajmah/2017/29433

17. Robbins SP, Judge TA. Organizational Behaviour. Boston: Pearson; 2013.

18. Nibbelink CW, Brewer BB. Decision-making in nursing practice: An integrative literature review. J Clin Nurs. 2018;27(5-6):917-28. https://doi.org/10.1111/jocn.14151 PMid:29098746

19. Lee TT. Nursing diagnoses: Factors affecting their use in charting standardized care plans. J Clin Nurs. 2005;14(5):640-7. https:// doi.org/10.1111/j.1365-2702.2004.00909.x

PMid:15840079

20. Mbithi BW, Mwenda C, Karonjo J. Knowledge on nursing process among nurses in selected county referral hospitals in Kenya. Int J Sci Res Publication. 2018;8(11):25-30. https://doi. org/10.29322/ijsrp.8.11.2018.p8305

21. Farren AT. An educational strategy for teaching standardized nursing language. Int J Nurs Terminol Classif. 2010;21(1):3-13

22. Pertiwi B, Hariyati RT. The impacts of career ladder system for nurses in hospital. Enferm Clín. 2019;29(52):106-10. https://doi. org/10.1016/j.enfcli.2019.04.016

23. Top M. Organizational variables on nurses' job performance in Turkey: Nursing assessments. Iran J Public Health. 2013;42(3):261-71.

PMid:23641403 